$\exists$ Journal of Logic \& Analysis 10:6 (2018) 1-1

ISSN 1759-9008

\title{
Abraham Robinson (6 October 1918 - 11 April 1974)
}

\author{
EDITORS, Journal of Logic \& Analysis
}

\begin{abstract}
Abraham Robinson was born 100 years ago today in Waldenburg, Germany (now Wałbrzych, Poland). While he is best known today in the wider scientific community for the creation of Nonstandard Analysis, Robinson's work was of importance more broadly in model theory, and he contributed in other parts of mathematical logic as well as in many areas of classical and applied mathematics. He exemplified the aim of the Journal of Logic \& Analysis - to promote interaction between mathematical logic and other areas of mathematics. It is fair to say that the Journal of Logic \& Analysis would not exist had it not been for his work, although the journal did not begin until more than 30 years after his death. Therefore, we would like to take this opportunity to acknowledge his contribution and express our gratitude that we have been able to carry on, over the last 10 years, in a tradition of which he was a pioneer.
\end{abstract}

http://logicandanalysis.org/ 